\title{
Disaster Knowledge Gaps: Exploring the Interface Between Science and Policy for Disaster Risk Reduction in Europe
}

\author{
Kristoffer Albris $^{1} \cdot$ Kristian Cedervall Lauta $^{2} \cdot$ Emmanuel Raju $^{3,4}$
}

Published online: 12 February 2020

(C) The Author(s) 2020

\begin{abstract}
Expert scientific knowledge is fast becoming an integral part of disaster management, and, in the process, is changing the role of science for the reduction of disaster risks at the policy level. Yet science and policy operate in different domains between which there are often competing interests and modes of valuing knowledge. Based on research done as part of the research project Enhancing Synergies for Disaster Prevention in the European Union (ESPREssO), we discuss three major issues facing European Union member states with respect to the interface between science and policy for disaster risk reduction: knowledge transfer, disaster expertise, and risk awareness. In doing so, we hone in on three gaps: an epistemological gap, an institutional gap, and a strategic gap. We argue that these gaps can help explain underlying systematic challenges for the integration between science and policy for disaster risk reduction. These gaps need to be addressed by focusing on changes at the governance level.
\end{abstract}

Kristoffer Albris

kristoffer.albris@anthro.ku.dk

1 Department of Anthropology, Faculty of Social Science, and COPE - Copenhagen Center for Disaster Research, University of Copenhagen, 1353 Copenhagen, Denmark

2 Center for International Law, Conflict and Crisis, Faculty of Law, and COPE - Copenhagen Center for Disaster Research, University of Copenhagen, 2300 Copenhagen, Denmark

3 Global Health Section, Faculty of Health and Medical Science, and COPE - Copenhagen Center for Disaster Research, University of Copenhagen, 1353 Copenhagen, Denmark

4 African Centre for Disaster Studies, Unit for Environmental Sciences and Management, North-West University, Potchefstroom 2531, South Africa
Keywords Disaster governance $\cdot$ Disaster risk reduction - Europe $\cdot$ Knowledge sharing $\cdot$ Risk expertise $\cdot$ Science-policy interface

\section{Introduction}

Expert scientific knowledge is increasingly becoming an essential and integral part of disaster risk management systems. This development has consequently marked a change in the role of science for the management of risks and hazards at the policy level, including practices, plans, and ideas in the domain of disaster risk reduction. Nowhere is this more visible than in the European Union (EU), with its highly industrialized and technocratically governed societies. Although the EU and its member countries are making substantial progress to this end-not least through the newly created EU Disaster Risk Management Knowledge Centre (Poljanšek et al. 2017) — as we will outline and discuss in this article, challenges prevail in incorporating and integrating science and expertise into disaster risk reduction policies, plans, and strategies.

The changing role of science vis-à-vis disaster management and risk reduction is intrinsically tied to how disasters are perceived culturally and politically. While disasters were once viewed as God's wrath or as nature's unforeseeable rage, disasters are today understood in relation to our own (in)ability to prevent or predict them (Alexander 2000; Steinberg 2006). Disasters in this perception do not emerge solely from nature. In fact, as scholars have noted for at least half a century, natural disasters are not natural at all (O'Keefe et al. 1976). Instead, they are defined as the failure of a human system's ability to address complex interactions of interrelated processes of vulnerability between society and the environment (Oliver-Smith 1999; Wisner et al. 2004). The 
key concepts in modern disaster research-hazard, risk, vulnerability, and resilience (see Kelman 2018) -all point to the fact that disasters occur as a result of hazards interacting with social structures. Disasters, in other words, have social roots (Tierney 2014). Thus, the management of disasters today is dependent on the organization of society, and hence on our ability to integrate relevant knowledge into the institutional arrangements and policies that underpin our ability to address disaster risks (Lauta 2014a). Scientific expert knowledge plays a vital role towards this end, allowing us to learn from previous disasters by identifying best practices, producing risk assessments, and by refining models that anticipate future patterns of natural hazards.

Analyzing the changing role of science and expert knowledge in relation to disasters is relevant, not only in terms of how government systems are able to respond to disasters, but also how they perform in all phases of disaster risk management, including recovery, prevention, mitigation, preparedness, and risk reduction. Wrong or misinterpreted scientific input across the various phases of disaster risk management can potentially lead to disastrous losses for affected communities and individuals. The need for accurate knowledge, as well as shared understandings of the form, interpretation, and accountability of this knowledge, is therefore crucial. Although the recognition of this need is by no means new, the question of how to integrate expert knowledge so as to reduce disaster risks is perhaps more pressing and relevant than ever. The infamous penal case against six scientists in the aftermath of the 2009 L'Aquila earthquake for their failure to communicate the risks to the public, serves as a reminder of the stakes at play and the potentially devastating consequences of misrepresenting science (Alexander 2014; Lauta 2014b). L'Aquila is an extreme case, and does not represent the wide array of more systemic, cultural, and institutional issues with respect to how expert knowledge operates within and alongside disaster risk reduction plans and practices. For this, a broader and more systematic examination of the problems at hand is needed.

In this article, we provide an overview of the present challenges in the science-policy interface for disaster risk reduction across EU member states. The aim is to provide an analysis of existing gaps as well as opportunities in existing policies and practices for disaster risk reduction in Europe with respect to science and expert knowledge. Our central research question can be formulated in the following manner: What are the main challenges reported by EU member states with respect to the integration of scientific knowledge in disaster risk reduction plans and practices, and how this relates to underlying institutional and systemic issues of governance?

As a red thread running through our examination of these issues, we explore what kind of knowledge is presently sought after by policymakers and disaster management practitioners, what the present needs and gaps in knowledge production are from the perspective of the scientific domain, and what the balance is between public risk awareness and existing knowledge that informs policy and governance levels. We focus on three major issues reported across EU member states, which we have identified as part of the research conducted in the ESPREssO project (see Sect. 2): (1) barriers to the transfer of knowledge; (2) a lack of disaster expertise; and (3) persistent issues related to raising risk awareness. In analyzing the root causes of these issues, we hone in on three gaps: (1) an epistemological gap, that is different understandings of which types of knowledge are relevant and should be managed; (2) a strategic gap, that is a lack of common understanding of how to strategically use scientific and expert knowledge for disaster risk reduction planning; and (3) an institutional gap, that is the need for institutions and organizations that are able to absorb and transform expert knowledge. These three gaps, we argue, are central factors that help explain current challenges facing the sciencepolicy interface for disaster risk reduction. The article discusses the integration of science and policy for disaster risk reduction with respect to these three gaps at the level of governance, rather than discussing the role of scientific knowledge generally in disaster management, the means by which previous research has engaged with this issue (Weichselgartner and Pigeon 2015).

The present focus on the interface and relationship between science and policy in the context of disaster risks must also be seen in relation to the wider discussion regarding the role of science for policy. An analysis of how knowledge is being transferred to an imagined policy domain should depart from the perspective that the interface between science and policy is shaped by a range of competing interests from multiple actors-academic, political, and bureaucratic. Indeed, frictions and tensions that are endemic to science-policy interfaces writ large are also impacting the role of science for policy and decision making for disaster risk reduction throughout Europe.

\section{Methods and Article Structure}

The empirical material underpinning this article was collected as part of the EU-funded H2020 project Enhancing Synergies for Disaster Prevention in the European Union, or ESPREssO ${ }^{1}$ The project identified gaps and best practices across three challenges: the science-policy interface,

\footnotetext{
${ }^{1}$ Further information about the project and its findings are available on the project website: http://www.espressoproject.eu. Accessed 21 Jan 2019.
} 
the lack of integration between disaster risk reduction and climate change adaptation policies, and transboundary crises management across EU member states. These three challenges were analyzed in the context of Italy (Zuccaro et al. 2017), Germany (Marx et al. 2017), France (Ettinger et al. 2017), Switzerland (Booth et al. 2017), the United Kingdom (UK) (Amaratunga et al. 2017a), and Denmark (Lauta et al. 2017a). A review report for each country was produced. A report focusing on these challenges from an EU perspective was also prepared (Lauta et al. 2017b).

The reports are based on a thorough review of academic as well as policy literature. A total of 91 semistructured interviews with key actors, experts, and stakeholders working on disaster risk reduction and climate change adaptation issues in each of the countries (as well as EU and global actors) were also conducted. These interviews aimed at bringing into light what stakeholders and experts see as the main challenges with respect to disaster risk reduction work from their respective positions. Interview questions included asking about the extent to which: (1) disaster risk reduction work receives the political attention and fiscal resources it needs to function; (2) the extent academic and scientific knowledge is being incorporated into policy discussions; and (3) changes that occur within the academic and scientific disciplines, and the kinds of research priorities such changes bring forth, which affect policy and DRR effectiveness.

A detailed presentation of the data collection and analysis carried out for each country can be found in the respective national reports on the project website. ${ }^{2}$ This article builds on the groundwork presented in these reports, but extends the analysis by situating the issues within the broader scientific literature on disaster management policies and scientific knowledge. The article thus draws on the insights from the ESPREssO reports in a synthesized manner, highlighting trends that cut across countries in the EU member states. Where relevant, specific points from the national reports are mentioned, and points raised by interviewees are also included where relevant.

Although each national report was prepared and written by individual project partners and researchers, the data collection and analysis efforts were coordinated to ensure consistency through regular review meetings and the use of standard protocols and templates. The surveyed countries do not represent all EU member states, but together point towards issues that concern the application and use of science in disaster management and risk reduction policies and institutional arrangements.

\footnotetext{
2 The national reports can be found as appendices in the synthesized report (Amaratunga et al. 2017b), deliverable 2.1 of the ESPREssO project. http://www.espressoproject.eu/images/deliverables/ ESPREssO_D2.1.pdf. Accessed 21 Jan 2019.
}

The article is structured into two main sections (Sects. 3 and 4). Section 3 explores the present landscape of the science-policy interface in the context of disaster management, and specifically disaster risk reduction, in terms of the aforementioned three central issues. Section 4 offers an analysis of the three issues identified in the previous section by examining them through the lens of the three gaps mentioned earlier. Finally, we offer our conclusions.

\section{Issues in the Interface Between Science and Policy for Disaster Risk Reduction}

Over the course of the last century, science has substantially increased its influence on public decision making across policy domains. In their role as advisers, some authors claim that scientists have emerged as a fifth branch of government (Jasanoff 1990). Others have called attention to the rise of professional experts as being a marker of modernity (Perkin 1989) or have dubbed our age the "age of assessment" (Rayner 2003, p. 164). This has given rise to the idea of the science-policy interface, which can be defined as social processes and relations between scientific experts, policymakers, and other actors in the domain of policy making "which allow for exchanges, co-evolution, and joint construction of knowledge with the aim of enriching decision-making" (Van den Hove 2007, p. 815). Despite continuous complaints from scientists that politicians do not heed the calls of scientists to meet the challenges of the day (Gluckman 2016), the fact is that science is becoming increasingly more important for society, not less (Jasanoff 2013). This has major implications for both realms: from the perspective of policy we can criticize it as an ongoing depoliticization and "scientification" of politics (Weingart 1999); while from the perspective of science, it leads to an instrumentalization and politicization of science, coinciding with a tendency for members of the public to oppose the perceived authority of science (Irwin and Wynne 2003). While the role of scientists and researchers are often messier and context dependent than official reports might convey (Spruijt et al. 2014), and policymakers might be more prone to use the advice of scientists when it fits with an already formulated political agenda, the increasing reliance on scientists and experts does present new challenges such as the unclear responsibility of scientific advisors if policies have adverse effects. This is perhaps more consequential in the reduction of disaster risks compared to most other domains where knowledge and policy are intertwined (Lauta 2014b).

Yet the field of disaster risk reduction is by no means isolated from general issues that create frictions in the science-policy interface; there are many such instances. First, as scholars have pointed out, when scientists act as policy 
advisors, their roles are shaped by the issues they are brought into advise on, as well as their personal values and type of expertise (Spruijt et al. 2014). Second, when included in the policy domain, scientists often face having to deal with a variety of so-called trade-offs in which the communication of expert knowledge-for instance the uncertainty of scientific findings - needs to be altered to fit a given context (Sarkki et al. 2014). And, as Birkland (1998) has pointed out, massive public concern following large disasters often turns these discourses into focusing events, which often (but not always) lead to policy changes. The significance of expert scientific knowledge in the process of making policy changes is therefore always contingent upon political agenda setting and shifting public attention.

These factors do not exhaust the issues with regard to how science is (and is not) incorporated into policy making. Yet they point to the fact that within the policy domain and the policy cycle, scientists and experts have to navigate a bureaucratic field in which policymakers do not simply listen to the advice of scientists and implement their suggestions into policy. Furthermore, the transfer of knowledge is not necessarily determined to have an impact, as there are certain kinds of knowledge to which policymakers and decision makers might not want to listen.

In disaster situations, the dilemmas inherent in the relationship between science and policy seem to be intensified. Disasters accelerate the policy domain's need for speed, which is contrasted by the science domain's need for time, reflection, and thoroughness. While policy changes, informed by scientific insights, might come about in the wake of disasters and emergencies, research suggests that this is not necessarily always the case (Birkland 2006). It seems clear then that there is a need to continuously examine areas of friction in the science-policy interface for disaster risk reduction if countries are to utilize the most up to date expert knowledge in preparing for future disasters.

According to the United Nations International Strategy for Disaster Reduction, disaster risk reduction is "the concept and practice of reducing disaster risks through systematic efforts to analyze and manage the causal factors of disasters, including through reduced exposure to hazards, lessened vulnerability of people and property, wise management of land and the environment, and improved preparedness for adverse events" (UNISDR 2009). The increasing focus on disaster risk reduction rather than an isolated focus on disaster response and recovery points towards an understanding that risk reduction can decrease both human and economic costs of disaster (Schreve and Kelman 2014). Thus, at the very heart of studying the efforts to reduce disaster risks, is to understand how knowledge is feeding into policy processes (Weichselgartner and Pigeon 2015), as outlined in this section.

In the following, we outline three key issues that we believe underpin concerns with addressing the integration of science in disaster risk reduction work from the perspective of scientists and/or experts, policymakers, disaster risk practitioners, and the general public. Given the nature of the research, these issues are meant to be indicative of trends rather than representative of the challenges facing all EU member states. As a recent report on the role of science in disaster risk management in the EU highlighted, EU member states tend to have a high degree of involvement of scientists and experts. However, the report also notes that "the use of scientific results and support may be limited in practice and the possibility to overcome the problems of integrating science in disaster risk management is narrow" (De Groeve and Valles 2015, p. 2). In other words, the findings presented in this article appear to be in accordance with perspectives presented elsewhere.

\subsection{Knowledge Transfer}

A major issue facing the interface between science and policy in disaster risk reduction is the lack of platforms and structures that not only enable sharing of knowledge between researchers and government institutions, but also enables the application of knowledge in policies (Amaratunga et al. 2017b). Generally, there is a desire for scientists and researchers working on disaster risk reduction and climate change adaptation issues to be more included in decision and policy making. Conversely, a general recognition of the importance of science and research to inform policy from the side of the policymakers also exists. This is exemplified in a growing number of networks and conference events that include both practitioners, university academics, and other relevant stakeholders (Booth et al. 2017; Lauta et al. 2017a; Marx et al. 2017), which is also visible at the EU level with the creation of the Disaster Risk Management Knowledge Centre (Lauta et al. 2017b). Risk web-platforms and related online repositories for knowledge sharing, such as the United Nations Prevention Web, also indicate that the tides are changing with respect to the perceived relevance of scientific knowledge in policy (Antofie et al. 2018). Many national examples of such arrangements also exist. The German Climate Consortium has brought together several scientific institutions since 2008 to synthetize scientific findings on climate change (Marx et al. 2017). In Switzerland, the recognition of the issue of knowledge transfer and sharing has given rise to the creation of The Mobiliar Lab for Natural Risks in $2013,^{3}$ a private/public partnership hosted at Universität Bern to bridge the interdisciplinary gap between science and disaster risk management practice (Booth et al. 2017).

Yet despite the existence of such examples, substantial challenges still prevail in allowing scientific research and

\footnotetext{
${ }^{3}$ See: https://www.mobiliarlab.unibe.ch/. Accessed 21 Jan 2019.
} 
technological innovations to have a real impact in the domains of governance and policy. There is a need for synthesis and compilation of lessons learned. As reported by stakeholders and interviewees in the national reports, it is not enough to launch projects and programs if the lessons-learned and best practices do not subsequently lead to innovation in terms of strengthening disaster risk reduction policies and plans. There needs to be innovation, as one interview respondent in the study from Denmark phrased it (Lauta et al. 2017a, p. 14), "to challenge the way we have done things and do things differently." There is thus a need for more mediating and facilitating actors, institutions or platforms, which enable a more efficient, productive, and satisfying transfer of knowledge. Training and attracting employees that can act as intermediaries and translators between academia and policy - which in the context of France have been referred to as "mediators of science" (Ettinger et al. 2017) — could be one way of addressing this issue. Another logical way forward to address this issue is to facilitate arenas, events, and platforms that allow for collaboration and synthesis of research across universities and research institutions in ways that go beyond the first step of enabling knowledge sharing (Lauta et al. 2017a).

In addition, disaster risk knowledge is increasingly produced, shared, and analyzed through means of crowdsourcing and on cooperative digital platforms (Poblet et al. 2014). Developments such as digital humanitarianism (Meier 2015), collective mapping tools, and systems for locating missing persons in emergencies are evidence of the way in which citizen-science trends are entering into disaster risk reduction practices. This points to the fact that the kinds of knowledge relevant for disaster professionals and disaster researchers are increasingly becoming more public and more diverse.

\subsection{Disaster Expertise}

Across several of the European countries examined in the ESPREssO project, a lack of priority in vulnerability assessments at the national, regional, and local levels has been reported (Ettinger et al. 2017; Lauta et al. 2017b; Zuccaro et al. 2017). The need for more complex and nuanced risk assessments that also take into account social and economic vulnerabilities is in line with both developments of research on disaster vulnerability (Wisner et al. 2004) as well as the emergence of international frameworks such as the Sendai Framework for Disaster Risk Reduction 2015-2030 (UNISDR 2015). ${ }^{4}$ These developments highlight the inadequacy of traditional risk

\footnotetext{
${ }^{4}$ See, for example, Priority 1 of the Sendai Framework. https://www. unisdr.org/files/43291_sendaiframeworkfordrren.pdf. Accessed 21 Jan 2019.
}

assessments based mainly on hazard data. The relevance for the science-policy interface is clear; if policymakers are to make better decisions regarding preventive and risk-reducing measures, then such decisions must be based on variables that point towards vulnerabilities of a broader kind than exposure to hazards. In Italy, for instance, a gap has been identified in terms of the lack of methodologies and tools for building comprehensive and holistic risk assessments (Zuccaro et al. 2017).

Yet the crucial question pertains not so much to the production of knowledge itself, but that there seems to be a lack of experts capable of conducting cutting-edge risk assessments within the new paradigm of vulnerability and resilience rather than focusing narrowly on hazards, which in turn is tied to the fact that social vulnerability is poorly understood (Aitsi-Selmi et al. 2016). There is a need to focus more on educating experts with an up-to-date understanding of disasters both in the context of universities and research institutions, as well as in government agencies and in the policy domain, where advice is given to decision makers. Related to this, and as highlighted in the Danish, Italian, French, and the UK contexts, there is the lack of disaster risk reduction education and awareness in schools and educational institutions (Amaratunga et al. 2017a; Ettinger et al. 2017; Lauta et al. 2017a; Zuccaro et al. 2017). There is general agreement that strategies for including disaster risk reduction and climate change adaptation perspectives in educational contexts should be prioritized more in order to educate a skilled workforce in both public and private contexts, and to raise public awareness, which is the focus in the following section.

\subsection{Risk Awareness}

The third issue pertains to the question of how scientific knowledge about risk makes an impact on how public institutions as well as populations perceive risk, to what extent institutions and individuals are even aware of risk, and how or whether a perception of risk leads to greater levels of preparedness. This is a topic rife with complexity. As Tierney (2014) has discussed, the study of risk perceptions has a long history. This record spans different paradigms and research programs from psychometric approaches (Slovic 1987), to the social amplification of risk framework (Pidgeon et al. 2003), to cultural approaches (Douglas and Wildavsky 1982). Despite decades of intensive research into risk perception and awareness, issues continue to exist; the problems outlined by earlier research programs seem to a large extent to be the same today. For instance, because ordinary citizens are generally not familiar with scientific probabilities, which underpin most risk assessments, there is a growing need to enable individuals to manage probabilistic information in order to 
decide whether or not to adopt countermeasures to mitigate risks (Wachinger et al. 2013). For the UK, it was found that even when government resources are committed to raising risk awareness, those at risk tend to choose to follow their own subjective risk assessments (Amaratunga et al. 2017a). For Italy (Zuccaro et al. 2017), the results of surveys carried out in risk-prone areas show that in many cases, citizens are not aware of the risks to which their community is exposed (Barberi et al. 2008; Crescimbene et al. 2014). In the case of France, a recent survey found that $78 \%$ of French people are unaware of what to do in the event that France's national alert system is triggered, and $63 \%$ were unaware of the risks they face (Ettinger et al. 2017). For Germany and Switzerland, it has been noted that despite the existence of a number of tools (infographics and risk maps) and guidelines for communicating messages from science to policy and to the public. Communicating these data in such a way that they reach the right target groups is still a great challenge (Booth et al. 2017; Marx et al. 2017). In the Swiss context, not only is scientific terminology difficult to interpret for nonexperts, but so are the visualizations (maps, infographics, and so on) that are intended to ease the interpretative transfer between science, policy, and the public domain (Booth et al. 2017). In addition, the difficulty of raising awareness about risks, especially when no event has occurred in recent times, has been documented to be a central obstacle for effective disaster risk reduction work (Krüger et al. 2015).

Risk awareness among the general population is, in modern technological societies, intrinsically related to the development of new types of media and communication technologies. Even though the role of new media, especially social media, is generating new ways for emergency professionals to communicate with the public, and vice versa (Reuter et al. 2018), these developments also bring more complexities with them in terms of how the flow of communication to the public should be governed (Albris 2018).

There is also a growing concern that the technical language and jargon that permeate risk and vulnerability assessments hinder integrative processes between scientific understandings of risks, and limit the ability of the policy domain to translate these assessments into plans and policies (Hinkel 2010). As a result, actors adopt their strategies based on idiomatic conceptual understandings. Yet this issue is not only present in the science-policy interface. Even within scientific disciplines, there is a significant difference in the understanding of disaster and risk terminology (Kelman 2018), which makes it difficult to communicate scientific discourse to the policy world. The complexity of the subject necessitates an appreciation of these differences and requires an ability to draw on as much synergy as possible between various disciplines. This context also seems to have implications for the translation of knowledge and insights between disaster risk reduction and climate change adaptation domains, as reported for instance in the UK context (Amaratunga et al. 2017a).

\section{Disaster Knowledge Gaps}

In this section, we discuss three gaps that are central to understanding the underlying causes of the three issues outlined in the previous section: an epistemological gap, an institutional gap, and a strategic gap. The three gaps do not neatly correspond to the three issues, but cut across them. How the issues and gaps are intertwined is illustrated in Table 1.

\subsection{The Epistemological Gap}

What we call the epistemological gap refers to the fact that science and policy, and subdomains within each of these, have different interests and worldviews when it comes to the very conception of knowledge, and what it is to be used for. One of the reasons this gap exists is the sheer nature of social complexity rooted in disaster risk reduction issues. Scholars have argued that scientists, policymakers, and decision makers represent very different worlds that need to be reconciled (Marzocchi 2013; Dolce and Di Bucci 2015). Some of the differences between these worlds make it inherently difficult to integrate the results of research into disaster risk reduction practices. Scientists are generally reluctant to make premature statements about events over which there remains significant uncertainty; decision makers occupy a realm in which urgent decision making is a prerequisite. Following Knorr-Cetina (1999), we might say that the epistemological gap refers to the fact that the science and policy domains represent two different epistemic cultures.

A key reason why policymakers are prone to misunderstand the scientific and expert communities lies in the different scientific traditions (natural sciences, social sciences, humanities, and so on) and disciplines (geography, sociology, climatology, meteorology, legal science, among others) that seldom enter into dialogue and interdisciplinary problem-solving. Difficulties for policymakers in understanding science is further related to their "scientific illiteracy." As noted earlier, in several of the surveyed countries, the terminology and jargon of researchers has been noted as a problem (see Sect. 3.3). This relates both to public dissemination and risk awareness raising, as well as to the interface between public officials and researchers in understanding one another. Science, and academic knowledge production as such, obviously needs to operate with specific terminologies that enable a precise inquiry into the 
Table 1 Analysis of the three issues and three gaps with respect to the science-policy interface for disaster risk reduction in Europe

\begin{tabular}{|c|c|c|c|}
\hline & Epistemological gap & Institutional gap & Strategic gap \\
\hline $\begin{array}{l}\text { Knowledge } \\
\text { transfer }\end{array}$ & $\begin{array}{l}\text { The transfer of knowledge is a messy } \\
\text { process, as science must rest on a } \\
\text { basis of uncertainty, making it hard to } \\
\text { provide clear-cut policy } \\
\text { recommendations }\end{array}$ & $\begin{array}{l}\text { Institutional structures that can facilitate } \\
\text { transfer of knowledge from science to } \\
\text { policy, and vice versa, are often } \\
\text { nonexistent or ineffective }\end{array}$ & $\begin{array}{l}\text { Due to the lack of common strategic } \\
\text { visions, knowledge transfer tends to } \\
\text { take place within sectors rather than } \\
\text { across them, and in an ad hoc rather } \\
\text { than systematized manner }\end{array}$ \\
\hline $\begin{array}{l}\text { Disaster } \\
\quad \text { expertise }\end{array}$ & $\begin{array}{l}\text { Disaster experts are needed to act as } \\
\text { mediators of science for policy in } \\
\text { both policy and academic domains }\end{array}$ & $\begin{array}{l}\text { There is a lack of platforms and arenas in } \\
\text { which discussions and exchange of } \\
\text { best practices can occur between } \\
\text { scientists, practitioners, and } \\
\text { policymakers }\end{array}$ & $\begin{array}{l}\text { While international frameworks focus on } \\
\text { capacity building, risk education, and } \\
\text { cross-sectoral training, there is a lack of } \\
\text { efforts to invest long term at the } \\
\text { national and local levels }\end{array}$ \\
\hline $\begin{array}{l}\text { Risk } \\
\quad \text { awareness }\end{array}$ & $\begin{array}{l}\text { The need for specialized terminology } \\
\text { underpinning scientific inquiry } \\
\text { hinders communication with the } \\
\text { policy domain and the public }\end{array}$ & $\begin{array}{l}\text { Scientists are but one group in a } \\
\text { multitude of different stakeholders that } \\
\text { compete for funding and the attention } \\
\text { of policymakers }\end{array}$ & $\begin{array}{l}\text { A lack of communication and } \\
\text { identification of needs between the } \\
\text { scientific domain and the general public }\end{array}$ \\
\hline
\end{tabular}

phenomena studied. However, improving upon ways in which scientists and researchers can better communicate complicated material around the pressing matters inherent in disaster risk reduction is needed. This is not a question of merely "dumbing down" science, but rather to find new ways of communicating complex issues in comprehensible ways, for instance through mediators of science and employing officials in public institutions that have both theoretical and hands-on experience with disasters (see Sect. 3.2).

The problem of terminology merely reflects one aspect of a much deeper problem: uncertainty. As science and research runs on intellectual contestation and critique, and thus contingent and uncertain knowledge, it is often difficult to provide clear-cut conclusions to decision makers and policymakers in the transfer of knowledge from one domain to another (see Sect. 3.1). This has been the case for climate change mitigation (Lahsen 2005), but it also pertains to the domain of disaster risk reduction. Scholars have shown that "processes are characterized by an interplay of technical, social and economic discourses in ways both multi-scalar and cross-cultural in nature" (Wesselink et al. 2013, p. 3). Scientists therefore cannot be the only group that defines and assesses problems and risks. A more holistic approach is needed, where risk assessments are based on scientific advice, while corresponding to the cultural, ethical, and political elements of any given society (Gaillard and Mercer 2013). Decision makers and policymakers have a key role to play in this regard. While the output of scientific research is (ideally, at least) a nuanced recommendation based on probabilities and careful consideration of uncertainties, decision makers are forced to follow a Boolean, binary, logic when selecting a policy option for disaster risk reduction (Woo and Marzocchi 2012).
In the short term of a disaster situation, decision makers are often $\mathrm{p}$ rompted to provide an immediate response, often balancing low occurrence probabilities versus envisaged catastrophic consequences (Dolce and Di Bucci 2012). This is the case, for example, of short-term earthquake forecasting where models might show that the occurrence of a seismic sequence may increase the probability as much as a thousand times, but the absolute probability still remains very low (usually below 1\%). These probabilities represent a formidable challenge to those decision makers responsible for taking mitigating and risk reducing actions, because it is obvious that in this low probability environment any warning could very likely be a false alarm (Woo and Marzocchi 2012).

\subsection{The Institutional Gap}

The integration of science and policy for disaster risk reduction is not only a matter of dealing with different types of knowledge and the management of uncertainty. It is equally about governance and institutional building. The scientific community's role must be clearly identified in relation to the government system in question (municipalities, agencies, ministries, and so on) in order to effectively contribute to risk assessments and other central disaster risk reduction tasks. Because the connection between science and policy is considered to be a priority in implementing the Sendai Framework (Pearson and Pelling 2015), the central issue at stake is how to set up the most effective and useful institutional arrangements that allow the scientific community and scientists employed in government entities to contribute to disaster risk reduction.

Presently, however, the involvement of the scientific community is to a large extent dependent on the will of policymakers. Thus, we can speak of an institutional gap, 
in the sense that barriers for integration of science into policy for disaster risk reduction can be directly traced to the lack of new institutions, and changes to existing ones. The transfer of scientific evidence in disaster risk reduction into effective applications and decisions has been limited so far (see Sect. 3.1), despite a growth in risk reduction knowledge production (Weichselgartner and Pigeon 2015). This is not to say that there is an absence of widespread attention and awareness around this issue, as several recent reports and research studies attest (IPCC 2012; Southgate et al. 2013; Aitsi-Selmi et al. 2016; Poljanšek et al. 2017). Yet it is evident that institutional structures that facilitate knowledge transfer are lacking when the findings from the ESPREssO project are examined (Amaratunga et al. 2017b).

The issue of a lack of disaster expertise (Sect. 3.2) is a significant aspect of the institutional gap. The issue concerns not only the lack of risk experts in public governance institutions, but also in the private sector and nongovernmental organizations. One of the important aspects of this issue is also that there is a gap between academics and practitioners working on similar problems in disaster risk reduction, as well as in climate change adaptation, but who are seldom in dialogue due to a lack of platforms, arenas, and opportunities to initiate such dialogue. This indicates that the interfaces between science and policy can be thought of as "a complex terrain that it is best described as a multi-level system of governance and knowledge production" (Vogel et al. 2007, p. 351). In disaster risk reduction, there are many and varied stakeholders (see Sect. 3.3) who compete for attention and funding, both of which are abundant when disasters occur, but scarce when they are absent.

As academia is part of these stakeholder interactions, science itself - the practice of producing knowledge-is enmeshed in struggles for space in policy making for disaster risk reduction. Thus the characteristics of disaster risk reduction as a new paradigmatic field of knowledge in disaster research also impacts the dynamics of the sciencepolicy interface. Building on the definition by the UNDRR (formerly UNISDR) provided earlier, disaster risk reduction can be said to be defined by an attentiveness to the reduction of vulnerability, and a move from response and recovery towards resilience, preparedness, and prevention. But how disaster risk reduction plans and practices play out varies from context to context. Academically, disaster risk reduction has to a large extent been championed by social scientists (Wisner et al. 2004). It is still a challenge to incorporate such perspectives into the natural sciences dealing with hazards and risks (for example, hydrology, volcanology, or seismology) that aim at producing statistical risk assessment models, albeit that vulnerability models are fast becoming a core part of disaster analysis in the natural sciences as well. Nonetheless, the fact that disaster risk reduction perspectives have been advanced primarily by the social sciences (especially sociology, human geography, anthropology, and development studies) means that there is a gap between different fields of knowledge with respect to disaster research that needs to be taken seriously.

\subsection{The Strategic Gap}

The epistemological and institutional gaps refer to the fact that there is a lack of agreement about the nature and application of knowledge, and a lack of institutions that can facilitate the application of that knowledge between the two domains. The strategic gap refers to the lack of common visions on how to progress. One of the key issues for the strategic gap is that of communication.

There are few outlets for scientists and related policymakers to debate and discuss issues of relevance and strategical long-term outlooks. On the global stage, standards and international frameworks such as the Sendai Framework (UNISDR 2015) have proposed trajectories for the involvement of science in disaster risk reduction policies; at the local level, integration and knowledge transfer tends to take place in a sectorial fashion rather than in a cross- or multi-sectorial fashion (see Sect. 3.1). Research has shown that disaster risk reduction can potentially save more money compared to a traditional reliance on disaster response (Schreve and Kelman 2014). Although international frameworks such as Sendai place great emphasis on risk reduction and capacity development, including educating and nurturing of disaster expertise, there has not been a similar level of focus on such aims at the national and local levels, and often institutions dealing with risk reduction fail to see the need for training on integration across domains (see Sect. 3.2). As Lavell and Maskrey argue: "Specialized disaster risk reduction institutions lack the political authority or technical capacity to influence development sectors" (Lavell and Maskrey 2014, p. 269).

Accordingly, the formulation of common visions for the science-policy interface is rare at the national and local levels, although they might be present at the international and EU levels. Divergent objectives and priorities are identified as a challenge to disaster risk reduction, both within policy frameworks (Raju and van Niekerk 2013) and between policymakers and scientists (Weichselgartner and Kasperson 2010). Accordingly, this challenge is reciprocal in nature. Scientists for their part need to understand cultural and institutional nuances in order to create knowledge inputs for sustainable, holistic policies, while policymakers need to develop and embrace more nuanced ideas of innovative knowledge production for disaster risk reduction. 
In addition to a gap between science and policy, there is also a lack of communication between scientists and the general public. The issue of risk perception and public risk awareness, as highlighted earlier (Sect. 3.3), clearly demonstrates this communication gap at multiple levels. The issue of public risk perceptions being in conflict with scientific and expert risk assessments will perhaps always be present. Yet measures for experts to better understand the dynamics of public risk perceptions need to be a prioritization, as it might not always be a matter of a lack of communication but rather a matter of epistemological (see Sect. 4.1) and cultural factors (Douglas and Wildavsky 1982) leading to diverging risk perceptions. Finally, there is a communication gap not only between scientists and policymakers but also between different scientific disciplines, and a continuous prioritization of the natural sciences in hazard analysis and crisis management (De Groeve and Valles 2015).

\subsection{Analysis of the Three Gaps in Relation to the Three Issues}

In order to summarize the findings and discussions we have highlighted in the previous sections, Table 1 (Sect. 4) provides an analysis of how the three issues relate to the three gaps. The relevance of conducting such an analysis of correlation between the issues and the gaps is also to show how there are multiple factors and root causes at play when trying to come to grips with the barriers and obstacles that face the integration of science and policy for disaster risk reduction.

All three gaps ultimately relate to issues and challenges for governance, or how to reorganize political and legal frameworks in order to further the integration between science and policy in the domain of disaster risk reduction. While the three gaps as well as the three issues do not exhaust the challenges confronting the science-policy interface for disaster risk reduction in Europe, we argue that the focus on these provide a fruitful starting point for discussion.

It has to be acknowledged, however, that what we here refer to as the science-policy interface (following Van den Hove 2007), should take into consideration the sometimes conflicting interests between science and policy actors. In other words, we do not wish to adopt a normative deterministic understanding that supposes that science and research should and can always be made to bear on policy decisions, nor that all policy decisions necessarily benefit from scientific input. In many cases the two domains have very different understandings of what knowledge is, how to organize the production of knowledge, and what use knowledge can have in relation to risk reduction. Although risk reduction perspectives are now part and parcel of international frameworks such as Sendai and are embedded in practices advanced by institutions such as the Red Cross, disaster risk reduction is a field of knowledge that is still in the making in both academia and in practitioner contexts. What defines the type of expertise needed for professionals and academics in relation to disaster risk reduction is thus still an open question, but nonetheless centers on a focus on understanding the root causes of vulnerability, and on the fact that resources should be devoted to preparedness, prevention, and resilience, rather than only on response and recovery.

Despite such uncertainties, we do argue that scientific findings have been shown to have great potential for the benefit of societies in Europe and beyond with respect to disaster risk reduction policies and plans. As such, the analysis of the issues and gaps as presented in Table 1 outline ideal typical ways of conceptualizing challenges for disaster risk reduction that do not map onto the real world in a one to one manner, but act as helpful categories for discussion of actual policies and plans.

\section{Conclusion}

Modern disaster management is becoming increasingly complex, a fact that holds true at local as well as global levels. While the global stage debates the trajectories laid out in the Sendai Framework, at the national and local levels, disaster risk practitioners, policymakers, and experts are faced with the challenge of implementation in which the role of science is becoming ever more crucial and yet harder to put into practice. Policymakers are faced with prioritizing decisions for disasters. Disaster management is a domain in which there is not a single scientific discipline or a single government department or stakeholder that can be said to have an authoritative voice. Rather disaster management is a myriad of actors.

We have discussed the challenges that exist for the science-policy interface in the domain of disaster risk reduction in Europe, and hence the potential for creating stronger and more effective institutions, platforms, and strategies for dealing with disasters. First, we briefly highlighted three issues that the ESPREssO project has identified and which correlate with the existing literature in the field of science policy in disaster risk reduction: knowledge transfer, disaster expertise, and risk awareness. We then proceeded by presenting three gaps we argue can explain some, if not all, of the issues facing the sciencepolicy interface in disaster risk reduction: an epistemological gap, an institutional gap, and a strategic gap. The epistemological gap points to the fact that there are fundamentally different interests at play in what type of knowledge that scientists, researchers, and experts on the 
one hand, and policymakers and public officials on the other hand, see as valuable and necessary. The institutional gap indicates that there a number of different organizational and institutional barriers that prevent scientists and policymakers closer engagement with one another. And finally, the strategic gap shows that there is a lack of cooperation between the science and policy domains, to a large extent having to do with the lack of communication and shared mutual understandings of this interdependency.

The analyses of the three issues and the three gaps indicate a range of implications for practice as well as for research. First, while there is a recognition of the need for sharing knowledge between and across actors in the science, policy, and public domains, more insight into what actually works needs to be gained. Specifically, more research into comparing different cases and initiatives of knowledge sharing is needed to unearth how knowledge travels across domains, and especially how crowdsourcing developments impact the politics of knowledge for disaster risk reduction. Second, the turn to disaster risk reduction warrants an increased focus on vulnerability and on resilience, but it is less clear what forms of expertise are demanded of professionals in public institutions to lift the challenge of reducing risks. Third, more insight is needed into understanding the institutional and strategic barriers that hinder the integration of disaster risk reduction aims in relation to other policy domains, most notable climate change adaptation, but also environmental protection, urban planning, agricultural management, and more. Taken in combination, the three gaps analyzed in this article illustrate how the overall research agendas of scientists and experts on the one hand, and the actual problems of policymakers and decision makers on the other, render utopian the full integration of the two. However, there is an increasing need to further integrate the two trajectories going ahead. While recent progress is becoming evident in transferring science into disaster risk reduction (GFDRR 2014a, b; Poljanšek et al. 2017), the present article has sought to shed light on why the science-policy interface in disaster risk reduction faces considerable challenges in the decades to come. The hope is that these can help policymakers as well as scholars to rethink how to address the present need for more knowledge in disaster risk reduction constructively - as one thing seems certain: we will not need less knowledge going ahead.

Acknowledgements We wish to thank all the partners and stakeholders that participated in and contributed to the research project Enhancing Synergies for Disaster Prevention in the European Union (ESPREssO). We also wish to thank the stakeholders and experts that agreed to participate in interviews and surveys in the course of the research. The ESPREssO project received funding from the EC HORIZON2020 Programme under Grant Agreement No. 700342. The insights gathered as part of the ESPREssO project should be recognized as jointly produced by all the project partners. Finally, we wish to thank the anonymous reviewers who provided sound and constructive criticisms.

Open Access This article is licensed under a Creative Commons Attribution 4.0 International License, which permits use, sharing, adaptation, distribution and reproduction in any medium or format, as long as you give appropriate credit to the original author(s) and the source, provide a link to the Creative Commons licence, and indicate if changes were made. The images or other third party material in this article are included in the article's Creative Commons licence, unless indicated otherwise in a credit line to the material. If material is not included in the article's Creative Commons licence and your intended use is not permitted by statutory regulation or exceeds the permitted use, you will need to obtain permission directly from the copyright holder. To view a copy of this licence, visit http://creativecommons. org/licenses/by/4.0/.

\section{References}

Albris, K. 2018. The switchboard mechanism: How social media connected citizens during the 2013 floods in Dresden. Journal of Contingencies and Crisis Management 26(3): 350-357.

Alexander, D. 2000. Confronting catastrophe: New perspectives on natural disasters. Edinburgh: Dunedin Academic Press.

Alexander, D. 2014. Communicating earthquake risk to the public: The trial of the "L'Aquila Seven." Natural Hazards 72(2): $1159-1173$.

Amaratunga, D., R. Haigh, N. Dias, and K. Hemachandra. 2017a. Synthesis report of legal, policy and science approaches within the frame of disaster risk reduction (DRR) and climate change adaptation (CCA) - National Report The United Kingdom. Napoli, Italy: Enhancing Synergies for Disaster Prevention in the European Union (ESPREssO). http://www.espressoproject. eu/images/deliverables/ESPREssO_D2.1.pdf. Accessed 21 Jan 2019.

Amaratunga, D., R. Haigh, N. Dias, and C. Malalgoda. 2017b. ESPREssO project, synthesis report of existing legal, policy and science approaches in relation to DRR and CCA. Napoli, Italy: Enhancing Synergies for Disaster Prevention in the European Union (ESPREssO). http://www.espressoproject.eu/images/deli verables/ESPREssO_D2.1.pdf. Accessed 21 Jan 2019.

Antofie, T.E., B. Doherty, and M. Ferrer. 2018. Mapping of risk webplatforms and risk data: Collection of good practices. Publications Office of the European Union. https://doi.org/10.2760/ 93157.

Aitsi-Selmi, A., V. Murray, C. Wannous, C. Dickinson, D. Johnston, A. Kawasaki, A.-S. Stevance, and T. Yeung. 2016. Reflections on a science and technology agenda for 21 st century disaster risk reduction. International Journal of Disaster Risk Science 7(1): $1-29$.

Barberi, F., M.S. Davis, R. Isaia, R.E. Nave, and T. Ricci. 2008. Volcanic risk perception in the Vesuvius population. Journal of Volcanology and Geothermal Research 172(3-4): 244-258.

Birkland, T. 1998. Focusing events, mobilization, and agenda setting. Journal of Public Policy 18(1): 53-74.

Birkland, T. 2006. Lessons of disaster, policy change after catastrophic events. Washington, DC: Georgetown University Press.

Booth, L., A. Scolobig, and J. Jorin. 2017. Synthesis report of legal, policy and science approaches within the frame of disaster risk reduction (DRR) and climate change adaptation (CCA) National Report Switzerland. Napoli, Italy: Enhancing Synergies for Disaster Prevention in the European Union (ESPREssO). 
http://www.espressoproject.eu/images/deliverables/ESPREssO_ D2.1.pdf. Accessed 21 Jan 2019.

Crescimbene, M., F. La Longa, R. Camassi, N.A. Pino, and L. Peruzza. 2014. What's the seismic risk perception in Italy? Engineering Geology for Society and Territory 7: 69-75.

De Groeve, T., and A.C. Valles. 2015. Science policy interfaces in disaster risk management in the EU: Mapping the support provided by science in the EU Civil Protection Mechanism. Brussels: European Commission.

Dolce, M., and D. Di Bucci. 2012. Probabilità e protezione civile. Ambiente Rischio Comunicazione 4: 34-39 (in Italian).

Dolce, M., and D. Di Bucci. 2015. Risk management: Roles and responsibilities in the decision-making process. In Geoethics: Ethical challenges and case studies in earth science, ed. M. Wyss, and S. Peppoloni, 212-221. Amsterdam, Netherlands: Elsevier.

Douglas, M., and A. Wildavsky. 1982. Risk and culture. An essay on the selection of technical and environmental dangers. Berkeley and Los Angeles: University of California Press.

Ettinger, S., F. Gerard, G. Le Cozannet, M. Fontaine, G. Grandjean, and A. Baills. 2017. Synthesis report of legal, policy and science approaches within the frame of disaster risk reduction (DRR) and climate change adaptation (CCA)—National Report France. Napoli, Italy: Enhancing Synergies for Disaster Prevention in the European Union (ESPREssO). http://www.espressoproject.eu/ images/deliverables/ESPREssO_D2.1.pdf. Accessed 21 Jan 2019.

Gaillard, J., and J. Mercer. 2013. From knowledge to action: Bridging gaps in disaster risk reduction. Progress in Human Geography 37(1): 93-114.

Gluckman, P. 2016. The science-policy interface. Science 353(6303): 969.

GFDRR (Global Facility for Disaster Reduction and Recovery). 2014a. Managing risks for a resilient future. https://www.gfdrr. org/sites/gfdrr/files/publication/GFDRR_Strategy_Endorsed_ 2012.pdf. Accessed 21 Jan 2019.

GFDRR (Global Facility for Disaster Reduction and Recovery). 2014b. Understanding risk in an evolving world-Emerging best practices in natural disaster risk assessment. https://www.gfdrr. $\mathrm{org} /$ sites/default/files/publication/Understanding_Risk-Web_Ver sion-rev_1.8.0.pdf. Accessed 21 Jan 2019.

Hinkel, J. 2010. "Indicators of vulnerability and adaptive capacity": Towards a clarification of the science-policy interface. Global Environmental Change 21(1): 198-208.

IPCC (Intergovernmental Panel on Climate Change). 2012. Managing the risks of extreme events and disasters to advance climate change adaptation. A Special Report of Working Groups I and II of the Intergovernmental Panel on Climate Change, eds. C.B. Field, V. Barros, T.F. Stocker, D. Qin, D.J. Dokken, K.L. Ebi, M.D. Mastrandrea, K.J. Mach, G.-K. Plattner, S.K. Allen, M. Tignor, and P.M. Midgley. Cambridge and New York: Cambridge University Press.

Irwin, A., and B. Wynne. 2003. Misunderstanding science? The public reconstruction of science and technology. Cambridge: Cambridge University Press.

Jasanoff, S. 1990. The fifth branch: Science advisors as policymakers. Cambridge, MA: Harvard University Press.

Jasanoff, S. 2013. States of knowledge: The co-production of science and the social order. London: Routledge.

Kelman, I. 2018. Lost for words amongst disaster risk science vocabulary? International Journal of Disaster Risk Science 9(3): 281-291.

Knorr-Cetina, K. 1999. Epistemic cultures: How the sciences make knowledge. Cambridge, MA: Harvard University Press.
Krüger, F., G. Bankoff, T. Cannon, B. Orlowski, and E.L.F. Schipper. 2015. Cultures and disasters, understanding cultural framings in disaster risk reduction. New York: Routledge.

Lahsen, M. 2005. Seductive simulations? Uncertainty distribution around climate models. Social Studies of Science 35(6): 895-922.

Lauta, K.C. 2014a. Disaster law. Oxon: Routledge.

Lauta, K.C. 2014b. New fault lines? On responsibility and disasters. European Journal of Risk Regulation 5(2): 137-145.

Lauta, K., E. Raju, N.O. Erno, H.R. Kerr, and M.F. Kielberg. 2017a. Synthesis report of legal, policy and science approaches within the frame of disaster risk reduction (DRR) and climate change adaptation (CCA)—National Report Denmark. Napoli, Italy: Enhancing Synergies for Disaster Prevention in the European Union (ESPREssO). http://www.espressoproject.eu/images/deli verables/ESPREssO_D2.1.pdf. Accessed 21 Jan 2019.

Lauta, K., E. Raju, N.O. Erno, H.R. Kerr, and M.F. Kielberg. 2017b. Synthesis report of legal, policy and science approaches within the frame of disaster risk reduction (DRR) and climate change adaptation (CCA) —EU review. Napoli, Italy: Enhancing Synergies for Disaster Prevention in the European Union (ESPREssO). http://www.espressoproject.eu/images/deliver ables/ESPREssO_D2.1.pdf. Accessed 21 Jan 2019.

Lavell, A., and A. Maskrey. 2014. The future of disaster risk management. Environmental Hazards 13(4): 267-280.

Marx, S., G. Barbeito, K. Fleming, B. Petrovic, and A. Thieken. 2017. Synthesis report on disaster risk reduction and climate change Adaptation in Germany-National Report Germany. Napoli, Italy: Enhancing Synergies for Disaster Prevention in the European Union (ESPREssO). http://www.espressoproject.eu/ images/deliverables/ESPREssO_D2.1.pdf. Accessed 21 Jan 2019.

Marzocchi, W. 2013. Seismic hazard and public safety. EOS 94(27): 240-241.

Meier, P. 2015. Digital humanitarians. Boca Raton, FL: CRC Press.

O'Keefe, P., K. Westgate, and B. Wisner. 1976. Taking the naturalness out of natural disasters. Nature 260(5552): 566-567.

Oliver-Smith, A. 1999. What is a disaster? In The angry earth: Disaster in anthropological perspective, ed. A. Oliver-Smith, and S. Hoffman, 18-34. New York and London: Routledge.

Pearson, L., and M. Pelling. 2015. The UN Sendai framework for disaster risk reduction 2015-2030: Negotiation process and prospects for science and practice. Journal of Extreme Events 2(1): Article 1571001.

Perkin, H. 1989. The rise of professional society: England since 1880. London: Routledge and Kegan Paul.

Pidgeon, N.E., R. Kasperson, and P. Slovic. 2003. The social amplification of risk. Cambridge: Cambridge University Press.

Poblet M., E. García-Cuesta, and P. Casanovas. 2014. Crowdsourcing tools for disaster management: A review of platforms and methods. In AI approaches to the complexity of legal systems, ed. P. Casanovas, U. Pagallo, M. Palmirani, and G. Sartor, 261-274. Berlin: Springer.

Poljanšek, K., M. Marín Ferrer, T. De Groeve, and I. Clark. 2017. Science for disaster risk management 2017: Knowing better and losing less. Luxembourg: Publications Office of the European Union.

Raju, E., and D.Van Niekerk. 2013. Intra-governmental coordination for sustainable disaster recovery: A case-study of the Eden District Municipality, South Africa. International Journal of Disaster Risk Reduction 4: 92-99.

Rayner, S. 2003. Democracy in the age of assessment: Reflections on the roles of expertise and democracy in public-sector decision making. Science and Public Policy 30(3): 163-170.

Reuter, C., A.L. Hughes, and M. Kaufhold. 2018. Social media in crisis management: An evaluation and analysis of crisis 
informatics research. International Journal of Human-Computer Interaction 34(4): 280-294.

Sarkki, S., J. Niemelä, R. Tinch, S. Van den Hove, A. Watt, and J. Young. 2014. Balancing credibility, relevance and legitimacy: A critical assessment of trade-offs in science-policy interfaces. Science and Public Policy 41(2): 194-206.

Schreve, C.M., and I. Kelman. 2014. Does mitigation save? Reviewing cost-benefit analyses of disaster risk reduction. International Journal of Disaster Risk Reduction 10(part A): 213-235.

Slovic, P. 1987. Perception of risk. Science 236(4799): 280-285.

Southgate, R.J., C. Roth, J. Schneider, P. Shi, T. Onishi, D. Wenger, and V. Murray et al. 2013. Using science for disaster risk reduction. Report of the UNISDR Scientific and Technical Advisory Committee. Geneva: United Nations International Strategy for Disaster Reduction.

Spruijt, P., A. Knol, E. Vasileiadou, J. Devilee, E. Lebret, and A. Petersen. 2014. Roles of scientists as policy advisers on complex issues: A literature review. Environmental Science \& Policy 40: $16-25$.

Steinberg, T. 2006. Acts of God: The unnatural history of natural disaster in America. Oxford: Oxford University Press.

Tierney, K. 2014. The social roots of risk: Producing disasters, promoting resilience. Stanford, CA: Stanford University Press.

UNISDR (United Nations International Strategy for Disaster Reduction). 2009. Terminology on disaster risk reduction. Geneva: United Nations International Strategy for Disaster Reduction. https://www.unisdr.org/files/7817_UNISDRTerminologyEngl ish.pdf. Accessed 21 Jan 2019.

UNISDR (United Nations International Strategy for Disaster Reduction). 2015. Sendai framework for disaster risk reduction 20152030. Geneva: United Nations International Strategy for Disaster Reduction.

Van den Hove, S. 2007. A rationale for science-policy interfaces. Futures 39(7): 807-826.
Vogel, C., S.C. Moser, R.E. Kasperson, and G.D. Dabelko. 2007. Linking vulnerability adaptation, and resilience science to practice: Pathways, players, and partnerships. Global Environmental Change 17(3-4): 349-364.

Wachinger, G., O. Renn, C. Begg, and C. Kuhlicke. 2013. The risk perception paradox-Implications for governance and communication of natural hazards. Risk Analysis 33(6): 1049-1065.

Weichselgartner, J., and P. Pigeon. 2015. The role of knowledge in disaster risk reduction. International Journal of Disaster Risk Science 6(2): 107-116.

Weichselgartner, J., and R. Kasperson. 2010. Barriers in the sciencepolicy-practice interface: Toward a knowledge-action-system in global environmental change research. Global Environmental Change 20(2): 266-277.

Weingart, P. 1999. Scientific expertise and political accountability: Paradoxes of science in politics. Science and Public Policy 26(3): 151-161.

Wesselink, A., K.S. Buchanan, Y. Georgiadou, and E. Turnhout. 2013. Technical knowledge, discursive spaces and politics at the science-policy interface. Environmental Science and Policy 30: $1-9$.

Wisner, B., P. Blaikie, T. Cannon, and I. Davis. 2004. At risk: Natural hazards, people's vulnerability and disasters. London: Routledge.

Woo, G., and W. Marzocchi. 2012. Previsione operativa dei terremoti e decisioni. Ambiente Rischio Comunicazione 4: 21-25 (in Italian).

Zuccaro, G., A. Criscuolo, D. De Gregorio, A. Di Ruocco, F. Gallinella, M. Leone, and C. Martucci. 2017. Synthesis report of legal, policy and science approaches within the frame of disaster risk reduction (DRR) and climate change adaptation (CCA) National Report Italy. Napoli, Italy: Enhancing Synergies for Disaster Prevention in the European Union (ESPREssO). http:// www.espressoproject.eu/images/deliverables/ESPREssO_D2.1. pdf. Accessed 21 Jan 2019. 